\title{
Environmental Management: Pragmatic Suitability of Low Cost Activated Carbon in Lead (II)Ion Removal by Continuous Mode of Adsorption
}

\author{
R. Sivarethinamohan $* \dagger$ and S. Sujatha** \\ *Christ (Deemed to be University), Bangalore, India \\ **K. Ramakrishnan College of Technology, Tamil Nadu, India \\ †Corresponding author: R. Sivarethinamohan; mohan.dimat@gmail.com
}

Nat. Env. \& Poll. Tech.

Website: www.neptjournal.com

Received: 05-11-2020

Revised: $08-02-2021$

Accepted: 20-02-2021

\section{Key Words:}

Activated carbon

Breakthrough curve

Fixed-bed column

Heavy metal

\begin{abstract}
Heavy metals such as chromium, lead, and arsenic are usually present in trace amounts in natural waters but many of them are toxic even at very low concentrations. An increasing quantity of heavy metals in our resources is currently an area of greater concern, especially since a large number of industries are discharging their metal containing effluents into freshwater without any adequate treatment. Activated carbons show a significant ability in removing heavy metal ions from an aqueous solution by adsorption, which has been examined by many researchers. Activated carbon derived from Manilkarazapota tree-wood (MZTWAC), which was found to be a suitable adsorbent for the removal of lead ions through continuous adsorption mode, was examined in this paper. A breakthrough curve has been plotted to find the effect of initial concentration and adsorbent bed height in the adsorption of lead (II)ion through MZTWAC. The breakthrough time and the saturation time increased as the initial concentration increased from $40 \mathrm{mg} \cdot \mathrm{L}^{-1}$ to $60 \mathrm{mg} \cdot \mathrm{L}^{-1}$. The saturation time was in the incremental mode when the bed height was increased from $5 \mathrm{~cm}$ to $7 \mathrm{~cm}$ bed thickness for $40 \mathrm{mg} \cdot \mathrm{L}^{-1}$ concentration. Adams-Bohart's model perfectly fits with this fixed-bed column in the removal of lead(II) from an aqueous solution using MZTWAC. Activated carbon derived from MZTWAC is better suited for the purpose of detoxifying metal-contaminated wastewater.
\end{abstract}

\section{INTRODUCTION}

Heavy metals are defined as metallic elements that have a relatively high density compared to water. With the assumption that heaviness and toxicity are interrelated, heavy metals also include metalloids, such as arsenic, that are able to induce toxicity at a low level of exposure (Duffus 2002). Also, human exposure has risen dramatically as a result of an exponential increase of their use in several industrial, agricultural, domestic and technological applications (Bradl 2002). Heavy metals such as copper are essential in the (Stern 2010) exertion of physiological function in living organisms. They are important constituents of several key enzymes and play important roles in various oxidation-reduction reactions. However, an excess amount of such metals produces cellular and tissue damage leading to a variety of adverse effects and human diseases. For some including chromium and copper, there is a very narrow range of concentrations between beneficial and toxic effects (Tchounwou et al. 2010, Chang et al. 1996). Other metals such as antinomy ( $\mathrm{Sb}$ ), cadmium $(\mathrm{Cd})$, aluminum $(\mathrm{Al})$, copper $(\mathrm{Cu})$, arsenic $(\mathrm{As})$, and lead $(\mathrm{Pb})$, have no established biological functions and are considered as non-essential metals (Chang et al. 1996). In recent years, there has been an increasing, global public health concern associated with environmental contamination by these metals. Reported sources of heavy metals in the environment include industrial, domestic effluents, pharmaceutical, agricultural, and atmospheric sources $(\mathrm{He}$ et al. 2005). The pollution of the environment is prominent in source areas such as mining, metal-based production, and fabrication processes (Bradl 2002, He et al.2005).

Pollution due to lead ion contagion in water has become a serious concern lately. Lead ion pollution can have harmful impacts on human health and can affect the nervous system, digestive system, and cause brain damage leading to fatality (Awual \& Hasan 2014, Lim \& Aris 2014). Primary sources of lead ion pollution are the discharge of mining wastes, glass and chemical industries, battery manufacturing companies, and ceramic-based industries. Environmental Protection Agency (EPA) has set the maximum contaminant level goal for lead ions in drinking water at $0.05 \mathrm{mg} . \mathrm{L}^{-1}$ because lead is a toxic metal that can be harmful to human health even at low exposure levels (Guyo et al. 2015). Thus to lessen the detrimental impact of lead(II) ion contamination in the environment, it is necessary to treat the lead ion polluted water.

Several treatment methods like membrane filtration, ion exchange, chemical precipitation, electrodeposition, coag- 
ulation, the solvent extraction process, and adsorption. Of all the methods, adsorption is very effective due to its ease, cost-effectiveness, and superior extraction capacity. Many different adsorbents have been used for the removal of toxic metal ions such as green coconut shells (Sousa et al. 2010), wheat bran (Ozer 2007), waste fruit cortex (Kelly-Vargas et al. 2012), agave bagasse, activated carbon of de-oiled soya (Sujatha et al. 2017), chitosan impregnated with a cationic surfactant (Rouf \& Nagapadma 2015).

This study intended to assess the performance of the activated carbon, derived from Manilkara Zapota tree wood (MZTWAC), in the removal of lead ions through column adsorption from which its practical applicability can be confirmed. The dynamic behavior of the fixed-bed (continuous adsorption) column was described using a breakthrough curve. The effect of initial lead(II) ion concentration and the effect of bed height on the performance of lead (II) ion adsorption were described in the present study.

\section{MATERIALS AND METHODOLOGY}

Manilkara Zapota is a fruit-producing tree that grows extensively in India. The tree branches are collected from a garden in Tamil Nadu.

\section{MZTWAC Preparation}

The fabrication of MZTWAC includes phases mentioned in the authors' previous article (Sujatha \& Sivarethinamohan 2019). The carbon that passed through $150 \mu$ sieve and suspended in $90 \mu$ sieve was stored in an airtight container. MZTWAC (Sujatha \& Sivarethinamohan 2019) is shown in Fig.1.

\section{Continuous Flow Mode or Column Adsorption Mechanism}

The practical utility of an adsorbent in removing the pollutants from the wastewater can be assessed by the column

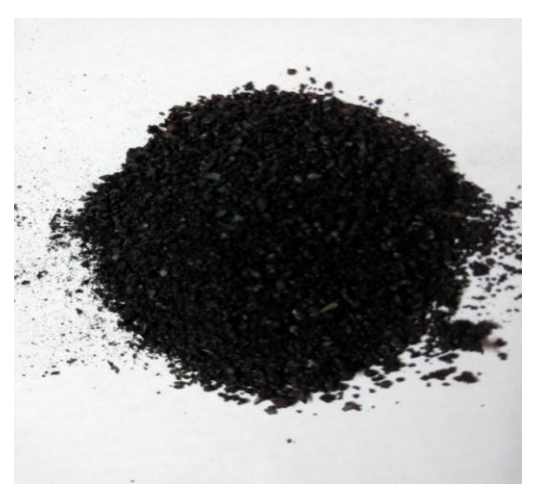

Fig. 1: MZTWAC (Sujatha \& Sivarethinamohan 2019).

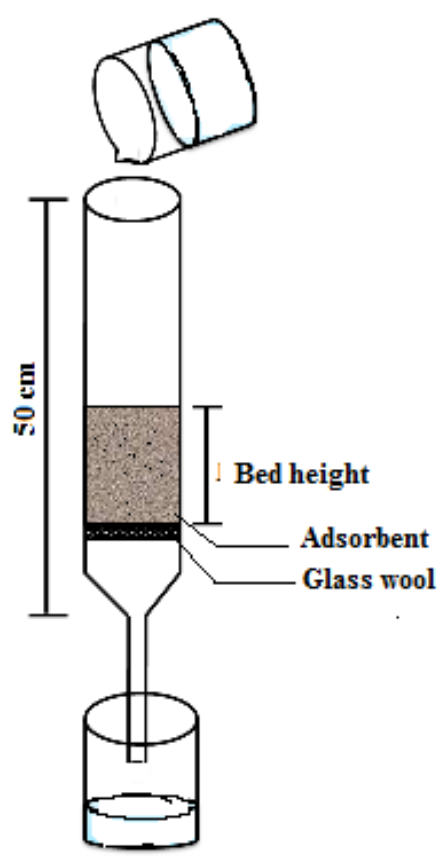

Fig. 2: Graphical representation of investigational setup for column adsorption studies

adsorption process. A fixed-bed column was used in the continuous mode adsorption process. A column made of glass with $1.75 \mathrm{~cm}$ diameter and a height of $50 \mathrm{~cm}$ was designed and used in the column study. The glass column had an opening at the bottom which could be adjusted by a valve. The column was filled with an adsorbent for a fixed depth over a layer of $1 \mathrm{~cm}$ of glass wool which was placed near the opening of the column. Fig. 2 shows the investigational setup for column studies.

To enable uniform filling, a glass rod was used for tapping and tamping. The filled carbon bed was completely dried by exposing it to sunlight for 3 days. The aqueous solution was filled in the column of fixed concentration of lead(II) ion. The input flow rate was preset as $2.5 \mathrm{~mL} \cdot \mathrm{min}^{-1}$. At a steady interval of time, the resultant solution was collected and analyzed spectrometrically. The effect of initial lead(II) ion concentration on the performance of lead (II) ion adsorption was experimented by altering the initial concentration of the lead(II) ion in the aqueous solution from $40 \mathrm{mg} . \mathrm{L}^{-1}$ to $60 \mathrm{mg} . \mathrm{L}^{-1}$ and the impact of the bed height was analyzed by altering the bed height from $5 \mathrm{~cm}$ to $7 \mathrm{~cm}$. The dynamic response/behavior of the adsorption column was calculated by the breakthrough time and profile of the breakthrough curve. To test the initial part of the breakthrough curve, Adams- Bohart's model was used. The model is particularly useful for estimating characteristic parameters of column experiments. 


\section{Adams- Bohart's Model Graph}

Adams-Bohart's model was applied to column information which describes the initial portion of the adsorption in continuous adsorption. Based on a theory of surface reaction, the Adams-Bohart' model assumes that equilibrium is not instantaneous and that the adsorption rate is proportional to the adsorption capacity of the adsorbent. This model establishes the basic equation describing the association between $\ln (\mathrm{Ct} / \mathrm{Co})$ and contact time ' $\mathrm{t}$ ' in a continuous adsorption process. The model is particularly useful for estimating characteristic parameters such as maximum adsorption capacity (No) and kinetic constant $\left(\mathrm{k}_{\mathrm{AB}}\right)$ used to determine a quasi-chemical kinetic rate expression. The data obtained in the fixed-bed column experiments was applied to Adams-Bohart's equation. Adams - Bohart's equation is as follows (Busto et al. 2016)

$$
\ln \frac{\mathrm{C}_{\mathrm{t}}}{\mathrm{C}_{\mathrm{o}}}=-k_{A B} C_{o} t+\frac{k_{A B} N_{o} Z}{U_{O}}
$$

where $\mathrm{C}_{t}$ is the equilibrium metal ion concentration (mg. $\left.\mathrm{L}^{-1}\right), \mathrm{k}_{\mathrm{AB}}$ is Adams- Bohart's kinetic constant in L.mg ${ }^{-1}$. $\min ^{-1}$. $\mathrm{N}_{\mathrm{o}}$ and $\mathrm{Z}$ are the adsorption capacity per unit volume of the adsorbent (saturation concentration in $\mathrm{mg} . \mathrm{L}^{-1}$ ) and the bed depth of the column $(\mathrm{cm})$, respectively. $\mathrm{U}_{\mathrm{o}}$ denotes the linear velocity $\left(\mathrm{cm} \cdot \mathrm{min}^{-1}\right)$. The values of $\mathrm{k}_{\mathrm{AB}}$ and $\mathrm{N}_{\mathrm{o}}$ were obtained from the plot of $\ln \left(\mathrm{C}_{\mathrm{t}} / \mathrm{C}_{\mathrm{o}}\right)$ versus time $\mathrm{t}$.

\section{RESULTS AND DISCUSSION}

\section{Characterization of MZTWAC}

Characterization studies had been undertaken on Fourier Transform Infrared (FTIR) analysis, Scanning Electron Microscope (SEM) analysis, X-Ray fluorescence (XRF), $\mathrm{X}$-Ray diffraction (XRD), and Brunauer- Emmett -Teller (BET) analysis. The characterization study revealed that the MZTWAC has got the potential to remove the lead(II) ion from an aqueous solution.

\section{Continuous Adsorption Study (Fixed-Bed Column Study)}

Column adsorption was carried with the designed column at a rate of flow of $2 \mathrm{~mL} \cdot \mathrm{min}^{-1}$. At an interval of $1 \mathrm{~h}$, the resultant solution from the column was collected and analyzed sphectrometrically. The test was repeated with different initial concentrations of lead(II) ion and with different bed heights of the adsorbents. A breakthrough curve was plotted between contact time in the $\mathrm{X}$-axis and $\mathrm{C}_{\mathrm{t}} / \mathrm{C}_{\mathrm{o}}$ in $\mathrm{Y}$-axis. Adsorption data was applied to the column model to get the information/data on the influence parameters.

\section{Impact of Initial Concentration on Adsorption}

To ascertain the performance and to optimize the adsorption process, the initial concentrations of lead (II)ion were altered between $40 \mathrm{mg} . \mathrm{L}^{-1}$ and $60 \mathrm{mg} . \mathrm{L}^{-1}$ by keeping the bed height $Z=5 \mathrm{~cm}$. The breakthrough curve is shown in Fig. 3. The breakthrough curve was linear because, initially, the equilibrium concentration was almost zero. The reason behind this was that at the initial stage the column bed completely adsorbed all the metal ions and as time passed, the bed was completely exhausted because of which it could not adsorb further metal ions from the solution. It was found from Fig. 3 that the unadsorbed metal ion concentration was increased by increasing the initial concentration of the lead(II)ion. The effectiveness of adsorption is the concentration difference between the solute in the adsorbent and the aqueous solution. This showed that the adsorbent bed saturated faster with a greater amount of initial concentration (Lim \& Aris 2014)

For $40 \mathrm{mg} . \mathrm{L}^{-1}$ initial concentration of lead(II) ion, Fig. 3 shows that the breakthrough time of adsorption was reached at $380 \mathrm{~min}$ and the saturation of the bed was reached at 1380 min. Breakthrough time of adsorption was reached at $350 \mathrm{~min}$ and saturation of the bed was reached at $1140 \mathrm{~min}$ for $60 \mathrm{mg} . \mathrm{L}^{-1}$ initial concentration of lead(II) ion.

\section{Impact of Bed Height on Adsorption}

The optimum performance of the continuous fixed-bed column adsorption with respect to bed height varied with the bed height from $5 \mathrm{~cm}$ and $7 \mathrm{~cm}$. The initial concentration was $40 \mathrm{mg} . \mathrm{L}^{-1}$ and a velocity of $2 \mathrm{~mL} \cdot \mathrm{min}^{-1}$ was kept constant.

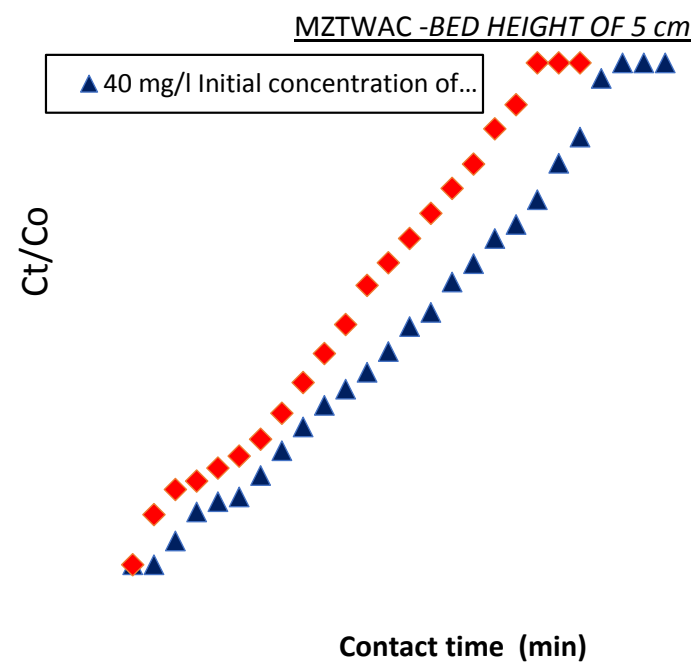

Fig. 3: Breakthrough curve for the impact of initial concentration of lead (II) ion with a bed height $\mathrm{Z}=5 \mathrm{~cm}$. 


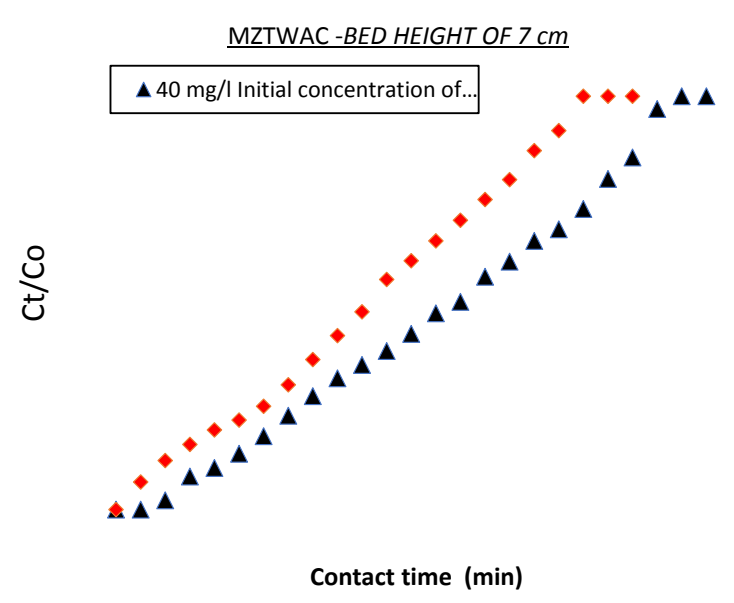

Fig. 4: Breakthrough curve for the impact of initial concentration of lead (II) ion with a bed height $\mathrm{Z}=7 \mathrm{~cm}$.

By comparing Fig. 3 and 4, it was revealed that as the bed height increased, the saturation time and breakthrough time extended (Biswas \& Mishra 2015), since more adsorbent particles were available for the adsorbate. It was found that the breakthrough time was attained at 350 minutes for a bed height of $5 \mathrm{~cm}$ bed height and 420 minutes for a bed height of $7 \mathrm{~cm}$.

\section{Adams-Bohart's Model for Fixed Bed Column}

The initial part of the adsorption was predicted by AdamBohart's model. Equation 1 is Adams-Bohart's column modeling equation. Adams-Bohart constants were derived from the graph (Fig. 5) drawn between the value of $\ln \left(C_{t} / C_{0}\right)$ versus time, where $C_{t}$ is the outlet metal ion concentration $(\mathrm{mg} / \mathrm{L}), \mathrm{k}_{\mathrm{AB}}\left(\mathrm{L} \cdot \mathrm{mg}^{-1} \cdot \mathrm{min}^{-1}\right)$ is Adams- Bohart's kinetic constant. $\mathrm{N}_{\mathrm{o}}\left(\mathrm{mg} \cdot \mathrm{L}^{-1}\right)$ and $\mathrm{Z}(\mathrm{cm})$ are the adsorption capacity per unit volume of the adsorbent column and the bed depth of the column respectively.

Adams-Bohart's column adsorption model with a bed height of $5 \mathrm{~cm}$ of lead(II) adsorption is shown in Fig. 5 which shows the Adams-Bohart's model curve of the adsorbate for column adsorption with the bed height pf $7 \mathrm{~cm}$.

Analysis and results of Adams-Bohart's constants for the fixed-bed column are summarized in Table 1. From Table 1 , it can be explained that the initial concentration of the

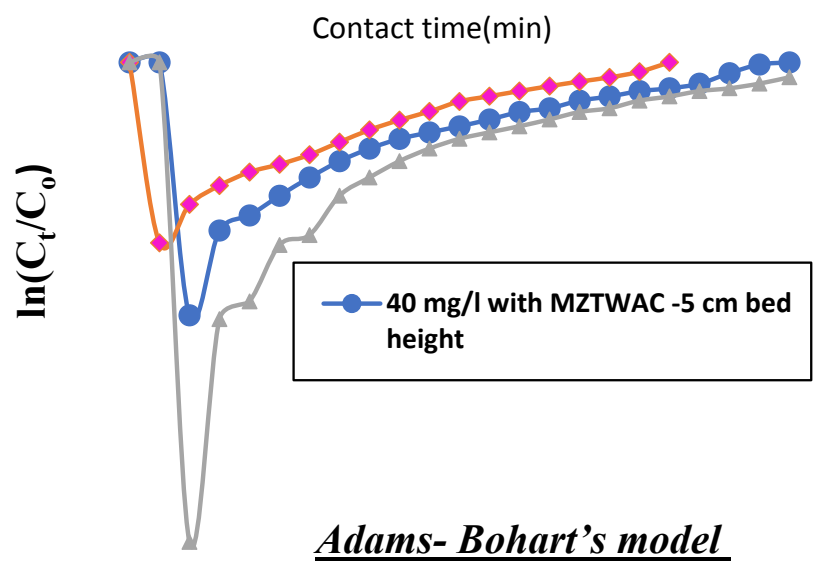

Fig. 5: Adams- Bohart's model on the impact of initial concentration of lead(II) ion.

solute increased $\mathrm{N}_{\mathrm{o}}$ (Sanchez-Machado et al. 2016) whereas $\mathrm{K}_{\mathrm{AB}}$ decreased. As the bed height increased from $5 \mathrm{~cm}$ to 7 $\mathrm{cm}, \mathrm{N}_{\mathrm{o}}$ decreased while $\mathrm{K}_{\mathrm{AB}}$ increased (Sanchez-Machado et al. 2016). The parameters that were applied in this study depicted the influence on the breakthrough for metal ions.

Table 1 shows that any alteration in the bed height of the adsorbent significantly affects the performance of the fixedbed column by reducing the speed of the exhaustion time. However, the alteration increased the initial concentration of the metal ion in an aqueous solution, which increased the speed of exhaustion of the adsorbent bed.

\section{CONCLUSION}

It is concluded that MZTWAC is suitable for removing the lead ion from an aqueous solution. The breakthrough curve depicted that as the initial concentration and impact of bed height increased, the adsorption of lead (II) ions increased. The breakthrough time and the saturation time were 380 minutes and 1380 minutes for $40 \mathrm{mg} . \mathrm{L}^{-1}$ initial concentration at $5 \mathrm{~cm}$ bed height. The breakthrough time and the saturation time were $350 \mathrm{~min}$ and $1140 \mathrm{~min}$ for $60 \mathrm{mg} . \mathrm{L}^{-1}$ initial concentration at $5 \mathrm{~cm}$ bed height. The breakthrough time and the saturation time were 420 minutes and 1620 minutes for $40 \mathrm{mg} . \mathrm{L}^{-1}$ for initial concentration at $7 \mathrm{~cm}$ bed height. The breakthrough time and the saturation time reduced as

Table 1: Adam- Bohart's parameters at different conditions for the adsorption lead(II) of fixed-bed column.

\begin{tabular}{|llllll|}
\hline Concentration of lead ion $(\mathrm{mg} / \mathrm{L})$ & Bed height $(\mathrm{cm})$ & $\mathrm{K}_{\mathrm{AB}}(\mathrm{L} / \mathrm{mg} \min )$ & $\mathrm{N}_{\mathrm{O}}(\mathrm{mg} / \mathrm{L})$ & Break through Time $(\mathrm{min})$ & Saturation time $(\mathrm{min})$ \\
\hline 40 & 5 & 0.000025 & 3344.34 & 380 & 1380 \\
60 & 5 & 0.000017 & 4859.28 & 350 & 1140 \\
40 & 7 & 0.000050 & 1788.64 & 420 & 1620 \\
\hline
\end{tabular}


the initial concentration increased. The perfect fit of AdamsBohart's model with the fixed-bed column showed that activated carbon derived from MZTWAC is better suited for the purpose of detoxifying metal-contaminated wastewater.

\section{REFERENCES}

Awual, M.R. and Hasan, M.M. 2014. A novel fine-tuning mesoporous adsorbent for simultaneous lead(II) detection and removal from wastewater. Sens. Actuators B Chem., 202: 395-403.

Biswas. S. and Mishra, U. 2015. Continuous fixed-bed column study and adsorption modeling: removal of lead ion from aqueous solution by charcoal originated from chemical carbonization of rubberwood sawdust. J. Chem., 2015: 1-9.

Bradl, H. (ed.) 2002. Heavy Metals in the Environment: Origin, Interaction, and Remediation. Elsevier/Academic Press, London.

Busto, Y., Palacios, E.W., Aloma, I., Rios, L.M., Cortez, M.F., Calero,M. and Year, M. 2016. Removal continuous studies of chromium (vi) using sugar cane bagasse. Chem. Eng. Trans., 52: 901-906.

Chang, L.W., Magos, L. and Suzuki, T. (ed.) 1996. Toxicology of Metals. Boca Raton. CRC Press, FL, USA.

Duffus, J. 2002. The heavy metals-a meaningless term? ( IUPA1C Technical Report). Pure Appl. Chem., 74(5): 793-807.

Guyo, U., Mhonyera, J. and Moyo, M. 2015. Pb(II) adsorption from aqueous solutions by raw and treated biomass of maize stover-a comparative study. Process. Saf. Environ., 93: 192-200.

Harvey, L.J. and McArdle, H.J. 2008. Biomarkers of copper status: A brief update. Br. J. Nutr., 99(S3): S10-3.

He, Z.L., Yang, X.E. and Stoffella, P.J. 2005. Trace elements in agroecosystems and impacts on the environment. J. Trace. Elem. Med. Biol., 19: 125-140.

Kelly-Vargas, K.,Cerro-Lopez, M., Reyna-Tellez,S., Bandala, E.R. and Sanchez-Salas, J.L. 2012. Biosorption of heavy metals unpolluted water, using different waste fruit cortex. Phys. Chem. Earth. 37: 26-29.
Lim, A.P. and Aris, A.Z. 2014. Continuous fixed-bed column study and adsorption modeling: Removal of cadmium(II) and lead(II) ions in the aqueous solution by dead calcareous skeletons. Biochem. Eng. J., 87: 50-61.

Ozer, A. 2007. Removal of $\mathrm{Pb}$ (II) ions from aqueous solutions by sulphuric acid-treated wheat bran. J. Hazard. Mater.,41(3): 753-761.

Rouf, S. and Nagapadma, M. 2015. Modeling of fixed-bed column studies for adsorption of azo dye on chitosan impregnated with a cationic surfactant. Int. J. Eng. Res., 6(2): 538.

Sanchez-Machado, D.I., Lopez-Cervantes, J., Correa-Murrieta, M. A. and Sanchez-Duarte, R.G. 2016. Modeling of breakthrough curves for aqueous iron (III) adsorption on chitosan-sodium tripolyphosphate. Water Sci. Technol., 74(10): 2297-2304.

Sousa, F.W., Oliveira, A.G., Ribeiro, J.P., Rosa, M.F., Keukeleire, D. and Nascimento, R.F. 2010 . Green coconut shells applied as adsorbents for removal of toxic metal ions using fixed-bed column technology. J. Environ. Manage., 91(8): 1634-1640.

Stern, B.R. 2010. Essentiality and toxicity in copper health risk assessment: Overview, update, and regulatory considerations. J. Toxicol. Environ., 73(2): 114-127.

Sujatha, S. and Sivarethinamohan, R. 2019. Investigation of detoxification nature of activated carbons developed from Manilkara zapota and deoiled soya. Mater. Today Proceed., 21(1): 663-668.

Sujatha, S, Venkatesan, G. and Sivarethinamohan, R. 2017. Principal determinants of toxicity reduction by de-oiled soya using multivariate statistics: Principal component analysis and multiple linear regression analysis. Appl. Ecol.Environ. Res., 15(3): 1717-1737.

Tchounwou, P.B., Newsome, C., Williams, J. and Glass K. 2008. Copper-induced cytotoxicity and transcriptional activation of stress genes in human liver carcinoma cells. Metal. Ions. Biol. Med., 10: 285-290.

Velazquez-Jimenez, L.H., Pavlick, A. and Rangel-Mendez, J.R. 2013. Chemical characterization of raw and treated agave bagasse and its potential as adsorbent of metal cations from water. Ind. Crop Prod., 43(1): 200-206. 